\title{
Students' Perspectives on Implementing Pedagogical Tasks in English Classroom
}

\author{
Erwin Pohan \\ English Education Department, Teacher Training and Education Faculty \\ Maritime Raja Ali Haji University \\ Tanjungpinang, Kepulauan Riau Province, Indonesia \\ epohan08@yahoo.com
}

\begin{abstract}
The outcome of learning English as a Foreign Language (EFL) in the classroom is the learners' ability to practice the target language or use language in their real life. The ability can be prepared and seen from their success of using target language (TL) in pedagogical tasks classroom. The purpose of the study is to analyze the students' perspectives on implementing pedagogical tasks in English classroom at the sixth-semester students of English Education Department of Teacher Training and Education Faculty of Maritime Raja Ali Haji University. The focuses are on (1) analyzing the students' understandings of conceptual pedagogical tasks in English classroom, and (2) predicting the effectiveness of implementation pedagogical tasks done by the lecturers in English classroom. The study is descriptive qualitative. The data were collected by asking the all students (66 students of class A and B) to fill in the questionnaires with Likert Scale to interpret the two focuses. The collected data were analyzed by calculating the students' responses based on the Ellis' framework for evaluating a task in [1]: (a) "student-based, which measures the degree to which students found the task useful and/or enjoyable; (b) learning-based evaluations, which attempt to measure the degree to which learning took place as a result of the task, (c) Retrospective evaluation can help teachers determine whether the materials can be used again, which activities work or not, and how the materials can be modified so as to increase task effectiveness in future lessons". The results showed that most of the students had positive perspectives toward both understandings conceptual task and pedagogical task, and teachers' implementing pedagogical tasks in their English classroom. And, The students' perceptions of their language acquisition on all subjects before and after implementing pedagogical are potential to be further researched.
\end{abstract}

Keywords--pedagogical tasks; target language; language acquisition; and evaluating a task

\section{INTRODUCTION}

Pedagogical tasks have been being implemented by teachers and learners in various instructional perspectives [1]-[14]. Besides, It is a part of Task-Based Language Teaching (TBLT) or central-design version of TBLT, and the basis for classroom interaction because they are designed classroom activities, specific interactional strategies, and the specific types of languages: skill, grammar, vocabulary. The outcomes of those are linguistic and communicative competence [6], [15].

Some studies of pedagogical tasks, in Asia and beyond, have shown that the experienced and inexperienced teachers in New Zealand can be detected in designing tasks and fulfilling tasks based on the Ellis' four criteria of a task [7], teacher's belief in implementing pedagogical tasks (communicative activities such as pair and group work) based on curriculum [16], [17], the improvement of young learners in the acquisition of vocabulary and grammar through input-based task (pedagogical tasks) [18]. Therefore, the teacher has an important role to help the students in acquiring the target language through pedagogical tasks practices in the classroom [5], [6], [8], [10], [19]

However, the study of pedagogical tasks comprehensively in Indonesian context is not optimal yet. Even though the 'task' word is written in English curriculum and almost all of English books contain 'task', the investigation about it on various perspectives are fewer than other foreign countries: China, Corea, and Iran, etc. This is in line with Ellis's statement [8] that the effectiveness of using TBLT is based on the proficiency of English language users orally or in written form.

Moreover, the study or students' perspectives on implementing pedagogical tasks at the Faculty of Teacher Training and Education, Universitas Maritim Raja Ali Haji is never conducted yet. Meanwhile, all lecturers give students many tasks to be practiced in the classroom. It is very urgent to be researched because there is no information whether or to what extent their activities are relevant to conceptual of the task or pedagogical tasks.

So, the purpose of the study is to explore the students' perspectives on task or pedagogical task and implementing pedagogical tasks in English classroom. And, the research questions are as follows:

1. To what extent can students understand the concept of the task and pedagogical task in English classroom?

2. How well do the students perceive the implementation of pedagogical tasks in English classroom?

Based on the research questions above, there are two focusses here. They are pedagogical tasks in English classroom and implementing pedagogical in English classroom. 


\section{A. Task and Pedagogical Tasks in English Classroom}

The task is the core activity of TBLT. All of the real-life activity with the four criteria such as a focus on meaning, some kind of 'gap', rely on the students own resources, and clearly defined outcome other the use of language [8] can be called task.

Reference [6] stated that pedagogical task is derived from the syllabus-based task, TBLT, and communicative language teaching (CLT). It is implemented target or real-world language which supported by enabling skills (language exercise \& communicative activities) and produced rehearsal tasks and activation tasks. Enabling skills means an ability of learner 'to take part in communicative tasks through mastery language system (grammar, vocabulary, pronunciation, etc.). It can be seen in language exercise and communicative activities. Meanwhile, rehearsal task refers to an activity of target language practiced inside and outside the classroom. And, Activation task is an activity of TL practiced inside the classroom only.

Pedagogical tasks focus on meaning rather than grammatical form in communicative language use [6], [20]. Communicative language is target language. Students who want to comprehend, manipulate, produce or interact in the target language (TL), mobilize their grammatical knowledge to express or convey meaning are called pedagogical tasks [6].

\section{B. Implementing Pedagogical in English Classroom}

The implementation of pedagogical tasks can be seen from the five aspects of language pedagogy such as group work, error correction, teacher role, learner contribution, and grammar [5]. Also, How to learn and teach target or real-world language can be practiced through pedagogical tasks in the classroom [6]. In other words, all communicative activities are pedagogical tasks or when the activity in the classroom is communicative, It has contained target language. For examples, role-play, simulation, taking part in a job interview, checking into a hotel, etc.

The effective implementing of task-based language teaching (TBLT), a teacher should "expose learners to good models of the target language (L2); take charge of the task in the wholeclass context; serves as a major source of input in TBLT; has a major role to play in providing feedback while students are performing a task; needs to perform multiple roles in TBLT; and is active in ensuring that a task is performing in ways that will foster learning"[8], [16], [20], [21].

In fact, as the English as a foreign language (EFL) learners, they sometimes use first language (L1). So, the use of mother tongue by the students during the pedagogical task is (a) to clarify the meaning of what the teacher said, (b) discussion of the requirements of a task, (c) how it might be tackled, (d) creating a sense of group cohesion, (e) reducing student anxiety [19]; and structure-based and information-gap tasks are referred to pedagogical tools. They can be used for language acquisition and promote attention to form and meaning [2].

However, Students' perception on implementing pedagogical tasks in their English classroom is related to five dimensions of the curriculum such as input, process, output, syllabus, methodology, and learning outcomes [15].

Then, there are three essential elements of implementing pedagogical tasks: language data, information, and opportunities for practice. Language data refers to samples of language skills (listening, reading, speaking, and writing); authentic \& nonauthentic data. Information means providing, processing, and getting linguistic information of target language system. Practice is employed the TL through the task, exercise, and activity [6].

\section{METHODS}

The study was descriptive qualitative and conducted between January and March 2017 on 66 students of two classes (A \& B) at the sixth-semester students of English Education Department, Teacher Training and Education Faculty of Maritime Raja Ali Haji University, Tanjungpinang, Kepulauan Riau Province - Indonesia.

There are 16 statements deal with pedagogical tasks. 7 statements are for conceptual of the task and pedagogical tasks and 9 statements are for implementing pedagogical tasks in English classroom as the objects of the study [6].

The data were collected through questionnaires. The students were asked to fill it anonymously in two different rooms. The researcher waited for them completing in fifteen minutes more or less. Then the data were tabulated to be analyzed.

And, the data was analyzed through the Likert Scale to interpret the two focuses: the students' understandings of conceptual pedagogical tasks in English classroom, and the effectiveness of implementation pedagogical tasks done by the lecturers in English classroom. The collected data were analyzed by calculating the students' responses based on the Ellis' (1997, 2003) framework for evaluating a task in [1]: (a) "student-based, which measures the degree to which students found the task useful and/or enjoyable; (b) learning-based evaluations, which attempt to measure the degree to which learning took place as a result of the task, (c) retrospective evaluation can help teachers determine whether the materials can be used again, which activities work or not, and how the materials can be modified so as to increase task effectiveness in future lessons". But, in this case, only point (a) student-based, (b) learning-based, (c) retrospective-based were used to analyze the collected data because the data were collected through questionnaires only. Then, the items of the questionnaires were given a numerical score (e.g., Strongly Agree $(S A)=5$ Agree $(A)=4$, Neutral $(N)=3$, Disagree $(D A)=2$, and Strongly Disagree $(S D)=1$. Then, there seven items for the first research question, 66 respondents, and the highest score is 5 (Strongly Agree). And, the highest score is $7 \times 5 \times 66=2310$ if all of the respondents choose Strongly Agree.

\section{RESULT AND DISCUSSION}

Based on the analysis, there were some findings dealing with the two research questions.

1) The students' understandings of task and pedagogical tasks

All the data were presented in Table I, on the 1st item, 'task is a communicative goal-directed'. There were 59 students of 66 choices Strongly Agree and Agree. It means that have known well on item 1; 6 of 66 neutral; and 1 of 66 Strongly Disagree. Item 2 is 'a task involved a primary focus on meaning'. There 
are 40 of 66 students responded SA and A. It means that the students have known well on item 2; there are 23 of 66 responded Neutral, and 2 of 66 responded DA. Besides, there was one student did not response item 2. Next, item 3 is 'a task has a clearly defined outcome'. There are 39 of 66 students responded SA and A. It means that students have known enough on item $3 ; 21$ of 66 responded N, and 2 of 66 responded DA. There were four students did not response item 3 . Item 4 is ' $a$ task has a nonlinguistic outcome'. There are 18 of 66 students responded SA and A; 47 of 66 students responded $\mathrm{N}$ and DA. It means that students have not known well on item 4 . There was one student did not response item 4 . Item 5 is 'A task is any activity in which the target language is used by the learner', there are 52 of 66 students responded SA and A; 9 of 66 students responded $\mathrm{N}$. There were five students did not response item 5 . Item 6 is 'Pedagogical task refers to learners' classroom work in comprehending, manipulating, producing or interacting in the language with focusing on meaning rather than forms', there are 44 of 66 students responded SA and A; 21 of 66 students responded N, DA, and SD. There was one student did not response item 6. Item 7 is Pedagogical tasks are designed to rehearse, in class, a communicative act they will carry out outside of the class (rehearsal task) and activate acquisition processes in the classroom only (activation task)', there are 38 of 66 students response SA and A; and 18 of 66 students responded $\mathrm{N}$. The total scores for Table I are $1655(71 \%)$ of 2310 for the highest scores. It means that the students have good understandings of task and pedagogical task conceptually. They (71\%) agree to the 7th statement in the Table I. Most of their responses are relevant to the previous studies. The students of International Islamic University Malaysia (IIUM) had positive perceptions in learning Arabic language as a second language with TBLT approach: they were motivated to learn it in the task [22].

TABLE I. STUDENTS' UNDERSTANDINGS OF TASK AND PEDAGOGICAL TASKS

\begin{tabular}{|c|c|c|c|c|c|}
\hline \multirow{2}{*}{ Item No. } & \multicolumn{5}{|c|}{ Responses } \\
\cline { 2 - 6 } & SA & A & N & DA & SD \\
\hline 1 & 4 & 55 & 6 & 0 & 1 \\
\hline 2 & 6 & 34 & 23 & 2 & 0 \\
\hline 3 & 6 & 33 & 21 & 2 & 0 \\
\hline 4 & 2 & 16 & 31 & 16 & 0 \\
\hline 5 & 11 & 41 & 9 & 0 & 0 \\
\hline 6 & 6 & 38 & 18 & 2 & 1 \\
\hline 7 & 7 & 31 & 28 & 0 & 0 \\
\hline
\end{tabular}

2) Students' perceives on implementing pedagogical tasks

The data in the Table II show the result of the student's responses toward the effectiveness of teachers in implementing pedagogical tasks in English classroom. there are nine indicators of the variable 'implementing pedagogical tasks'. Item 8 is 'teacher provides samples of language skills (listening, reading, speaking, and writing) in English classroom'. There are 63 of 66 students response SA and A. It means that the students perceive the teachers have provided samples of language skills well; 3 of 66 students response N; and no one DA and SD. Item 9 is 'teacher provides authentic data in English classroom'. there are 46 of 66 students response SA and A. It means that the teachers have provided authentic data in the classroom; 17 of 66 students response N; and 3 of 66 students response DA and SD. Item 10 is 'teacher provides non-authentic data in English classroom'. There are 15 of 66 students response SA and A; 35 of 66 students for N; and 16 of 66 students for DA and SD. Here, the students hesitate toward teachers' providing non-authentic data in their classroom or some teachers provided non-authentic data in the classroom while teaching. Item 11 is 'teacher provides linguistic information of target language system in English classroom'. There are 46 of 66 students response SA and A; 14 of 66 students for N; and 1 of 66 students for DA. Item 12 is 'teacher guides learners to process the information about how to go about learning the language in English classroom'. There are 55 of 66 students response SA and A; 10 of 66 students for N; and no one for DA and SD. Item 13 is 'teacher guides learners to get the information deductively and inductively in English classroom'. There are 50 of 66 students response SA and A; 15 of 66 students for N; and nobody for DA and SD. It means that teachers have guided learners to get the information deductively and inductively. Item 14 is "Teacher asks learners to practice the target language through "task" more frequently than "exercise", and "activity" in English classroom'. There are 31 of 66 students response SA and A; 20 of 66 students for N; and 15 of 66 students for DA and SD. Item 15 is "teacher asks learners to practice the target language through "exercise" more frequently than "task", and "activity" in English classroom'. There are 37 of 66 students response SA and A; 21 of 66 students for N; and 8 of 66 students for DA and SD. Item 16 is 'teacher asks learners to practice the target language through "activity" more frequently than "exercise", and "task" in English classroom". There are 48 of 66 students response SA and A; 18 of 66 students for N; and nobody chooses DA and SD. Based on the students' responses on item $14-16$, it clear that they are more familiar with 'activity' ( $72 \%$ for positive response) than 'exercise' (56\% for positive responses) and 'task' (47\% for positive responses) dealing with the teachers implementing pedagogical tasks in their classroom. So, the total scores on Table II are 2213 (74\%) of 2970 (the highest score).

TABLE II. IMPLEMENTING PEDAGOGICAL TASKS

\begin{tabular}{|c|c|c|c|c|c|}
\hline \multirow{2}{*}{ Item No. } & \multicolumn{5}{|c|}{ Responses } \\
\cline { 2 - 6 } & SA & A & N & DA & SD \\
\hline 8 & 30 & 33 & 3 & 0 & 0 \\
\hline 9 & 8 & 38 & 17 & 2 & 1 \\
\hline 10 & 2 & 13 & 35 & 14 & 2 \\
\hline 11 & 6 & 40 & 14 & 1 & 0 \\
\hline 12 & 19 & 36 & 10 & 0 & 0 \\
\hline 13 & 8 & 42 & 15 & 0 & 0 \\
\hline 14 & 11 & 20 & 20 & 10 & 5 \\
\hline 15 & 12 & 25 & 21 & 6 & 2 \\
\hline 16 & 18 & 30 & 18 & 0 & 0 \\
\hline
\end{tabular}

The findings are relevant to [23] stated that the learners in China had positive perspectives in learning English such as excited and beneficial participating in the task, perceiving their teachers as the facilitator, and tutor in learning strategies, the more participating in different tasks the better 'they evaluate their own performance' with the implementation of TBLT in their classroom.

\section{CONCLUSION}

The teaching phenomena in the classroom can be seen and found the solutions from the learners' perspectives. In this case, 
the sixth-semester students' perspectives of English education department of Teacher Training and Education Faculty of Maritim Raja Ali Haji University have shown that there is a relationship between teachers' teaching practices in the classroom with the students' understanding of the task and pedagogical tasks conceptually.

Based on the analysis, some EFL teachers have informed the students about the concept of the task and pedagogical task implicitly. It can be seen from their responses in line with the understandings ( $71 \%$ Agree). Even though most of them understand the concepts, there is a certain item that needs to be considered by the teacher in the future, namely, Item 4 is 'a task has a nonlinguistic outcome' (71\% Neutral, DA, and SD). It indicates the students did not understand it yet.

Then, the students' perspectives on implementing pedagogical task done by the teachers were positive $(72 \%$ Agree). They realize that some of the tasks given and done in the classroom are relevant to the effectiveness of applying pedagogical task: three essential elements of the approach such as language data, information, and practice [6]. in other words, some of the teachers have informed them indirectly or in unconsciousness. However, the students hesitate toward teachers' providing non-authentic data in their classroom or some teachers provided non-authentic data in the classroom while teaching. This must be concerned with the right selection, sequencing, and justifying it while teaching.

The students' perceptions of their language acquisition on all subjects before and after implementing pedagogical are potential to be further researched.

\section{ACKNOWLEDGMENT}

The author thanks the Dean of FKIP UMRAH, Abdul Malik who has given him permission toresearch at his English Education Department. And to all of the sixth-semester students of English Education Department of FKIP UMRAH who had taken part in the research. In addition, the research is financed by the author.

\section{REFERENCES}

[1] M. Calvert and Y. Sheen, "Task-based language learning and teaching: An action-research study," Lang. Teach. Res., vol. 19, no. August, pp. 226 $244,2015$.

[2] M. J. de la Fuente and M. J. De Fuente, "Classroom L2 vocabulary acquisition: investigating the role of pedagogical tasks and form-focused instruction,” Lang. Teach. Res., vol. 10, no. 3, pp. 263-295, 2006.

[3] H. Nassaji and Jun Tian, "Collaborative and individual output tasks and their effects on learning English phrasal verbs," Lang. Teach. Res., vol. 14 , no. 4 , pp. $397-419$, Oct. 2010 .
[4] Lasito and N. Storch, "Comparing pair and small group interactions on oral tasks,” RELC J., vol. 44, no. 3, pp. 361-375, 2013.

[5] G. Ogilvie and W. Dunn, "Taking teacher education to task: Exploring the role of teacher education in promoting the utilization of task-based language teaching," Lang. Teach. Res., vol. 14, no. 2, pp. 161-181, 2010.

[6] D. Nunan, "Task-Based Language Teaching," Task-Based Lang. Teach., pp. 1-15, 2004.

[7] R. Erlam, “' Im still not sure what a task is: Teachers designing language tasks,” Lang. Teach. Res., vol. 20, no. 3, pp. 279-299, May 2016.

[8] R. Ellis, "Taking the critics to task: The case for task-based teaching," Proc. CLASIC 2014, pp. 103-177, 2014.

[9] W. Littlewood, "The task-based approach: some questions and suggestions," ELT J., vol. 58, no. 4, pp. 319-326, Oct. 2004.

[10] J. Moser, J. Harris, and J. Carle, "Improving teacher talk through a taskbased approach,” ELT J., vol. 66, no. 1, pp. 81-88, 2012.

[11] A. F. Dobao, "Vocabulary learning in collaborative tasks: A comparison of pair and small group work," Lang. Teach. Res., vol. 18, no. 4, pp. $497-$ 520, 2014.

[12] R. Batstone, "Language form, task-based language teaching, and the classroom context," ELT J., vol. 66, no. 4, pp. 459-467, 2012.

[13] G. D. Keating, "Task effectiveness and word learning in a second language: The involvement load hypothesis on trial," Lang. Teach. Res., vol. 12 , no. 3 , pp. 365-386, 2008.

[14] C. J. Lim and S. Lee, "Pedagogical Usability Checklist for ESL/EFL Elearning Websites," J. Converg. Inf. Technol., vol. 2, no. 3, pp. 67-76, 2007.

[15] J. C. Richards, "Curriculum Approaches in Language Teaching: Forward, Central, and Backward Design," RELC J., vol. 44, no. 1, pp. 5-33, 2013.

[16] X. Zheng and S. Borg, "Task-based learning and teaching in China: Secondary school teachers' beliefs and practices," Lang. Teach. Res., vol. 18, no. 1, pp. 205-221, 2014.

[17] E. Pohan, E. Andhini, E. Nopitasari, and Y. Levana, "Teachers , Perceptions of Task-Based Language Teaching in English," 2016, vol. 9, pp. 256-265

[18] N. Shintani, "Input-based tasks and the acquisition of vocabulary and grammar: A process-product study," Lang. Teach. Res., vol. 16, no. 2, pp. 253-279, 2012.

[19] D. Carless, "Implementing task-based learning with young learners," ELT J., vol. 56, no. October, pp. 389-396, 2002.

[20] N. Galloway and H. Rose, "Using listening journals to raise awareness of global Englishes in ELT,” ELT J., vol. 68, no. 4, pp. 386-396, 2014.

[21] A. Panahi, "Binding task-based language teaching and task-based language testing: A survey into EFL teachers and learners' views of taskbased approach," English Lang. Teach., vol. 5, no. 2, pp. 148-159, 2012.

[22] M. Hashim, "Task-Based Language Teaching ( Tblt ) Approach in Learning Arabic Language: Students ' Voice," Int. J. Sci. Commer. Humanit., no. Ilc, pp. 1-12, 2014.

[23] Meng and Cheng, "College Students" Perceptions on the Issues of Taskbased Language Teaching in Mainland China,” J. Lang. Teach. Res., vol. Vol. 1, No. 4, p. 434-442, 2010. 